\title{
242. Studies on the Regional Distribution of the Monoamine Oxidase Activity in the Brains of Schizophrenic Patients
}

\author{
By Hiroshi Utena, Hajime Kanamura, Shigeo Suda, \\ Rikuro NAKAMURA, Yukiteru MACHIYAMA, \\ and Ryo TAKAHASHI
}

Neurochemical Laboratories, Department of Neuropsychiatry, Faculty of Medicine, University of Tokyo

(Comm. by Yushi Uchimura, M. J. A., Dec. 12, 1968)

Methamphetamine psychosis exhibits mental and behavioural symptoms entirely comparable to those of schizophrenia. Some behavioural traits such as a loss of initiative and an emotional flattening or apathy frequently persist for months after the use of drug is discontinued. Similar behavioural changes can be induced in a variety of animal species by a long-term administration of methamphetamine, which last for a month after the cessation of medication. ${ }^{8)}$ Thus it appears that the chronic methamphetamine intoxication in animals can be a model of schizophrenia in a study to find possible neurochemical correlates to the behavioural abnormalities in schizophrenia.

In a series of studies on methamphetamine intoxication, Utena and his associates ${ }^{2,8)}$ have found a parallelism between the course of behavioural changes in the intoxicated mice and the increase in brain serotonin (5-HT). Studies on the regional distribution of 5-HT, 5-hydroxytryptophan decarboxylase and monoamine oxidase (MAO) in the brain of intoxicated cats have revealed unique changes of 5-HT and MAO activity in the amygdala.2),6),8) The increase of 5 -HT in the amygdala is quite different from the changes in other regions of brain in that it is resistant to the normalizing action of chlorpromazine which has an alleviating effect on the behavioural aberrations of the intoxicated animals. There are no remarkable changes in the activities of 5-hydroxytryptophan decarboxylase and of MAO except that the MAO activity is decreased to the considerable extent in the amygdala. On the basis of these findings Utena and his co-workers have suggested that the amygdala might be related to the behavioural abnormalities in methamphetamine-intoxicated animals. A question arises here whether or not there is any change in the topographical distribution of the MAO activity in the brain of schizophrenic patients. 
Five brains from schizophrenic patients comprising 3 males and 2 females, 18 to 83 years of age, died from pneumonia, peritonitis, cancer of the rectum and strangulation after the 5 to 40 years course of schizophrenia and the same number of brains from patients, 3 males and 2 females, 54 to 70 years of age, died from cancer without the apparent mental illness were analysed for the distribution of the MAO activity in twenty-four regions. Brains were removed, packed in a polyethylene bag and transferred into a deep-freezer within 5 hours after the death of patients, and stored at $-20^{\circ}$ until analysed (21-300 days). The frozen brains were thawed at $4^{\circ}$ for several hours, then dissected in a cold room into the parts specified in the appropriate place. The dissected parts of the brain were put into a small glass vial with cap, frozen on solid $\mathrm{CO}_{2}$ and kept in a deepfreezer at $-20^{\circ}$. The determination of the MAO activity was carried out within 10 days after the dissection.

The MAO activity was determined according to the method described by Bogdanski et al. ${ }^{1)}$ with minor modifications. The incubation mixture, containing $1.0 \mathrm{ml}$. of homogenate (equivalent to $200 \mathrm{mg}$. tissue), $1.0 \mathrm{ml}$. of $0.3 \mathrm{M}$ phosphate buffer at $\mathrm{pH} 7.0$ and $0.5 \mathrm{ml}$. of distilled water or of $60 \mathrm{mM}$ Parnate (in a blank vessel) in a $10 \mathrm{ml}$. beaker, was incubated for 15 minutes at $37^{\circ}$ with shaking (90 strokes per minute), then added $0.5 \mathrm{ml}$. of $9 \mathrm{mM} 5-\mathrm{HT}$ and incubated for further 30 minutes. The reaction was stopped by adding $3.0 \mathrm{ml}$. of $2 \mathrm{~N} \mathrm{HCl}$ and the mixture was then centrifuged. A portion of supernatant was used for the determination of 5-HT by the method described by Udenfriend.7) Protein in the homogenate was determined according to the method of Lowry et al. ${ }^{3)}$ using bovine serum albumin as standard. The activity of enzyme was expressed in terms of $\mu$ moles 5 -HT destroyed per g. tissue/hr. or per mg. protein/hr.

Prior to the determination of MAO activities in human brains, the changes in the enzyme activity during the post-mortem period between the death and putting the excised brain into a deep-freezer

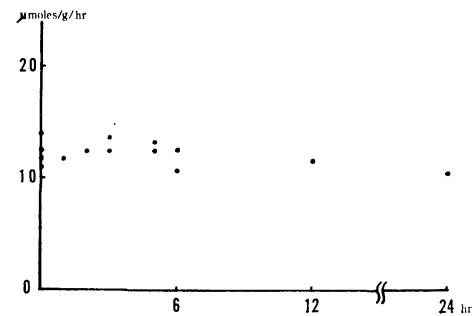

Fig. 1. Effect of leaving slaughtered rats at room temperature on the MAO activity in their brains.

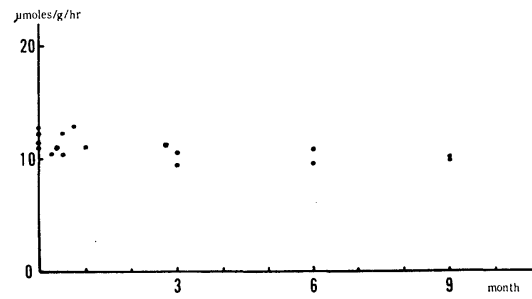

Fig. 2. Effect of storage of excised rat brains at $-20^{\circ}$ on their MAO activity. 


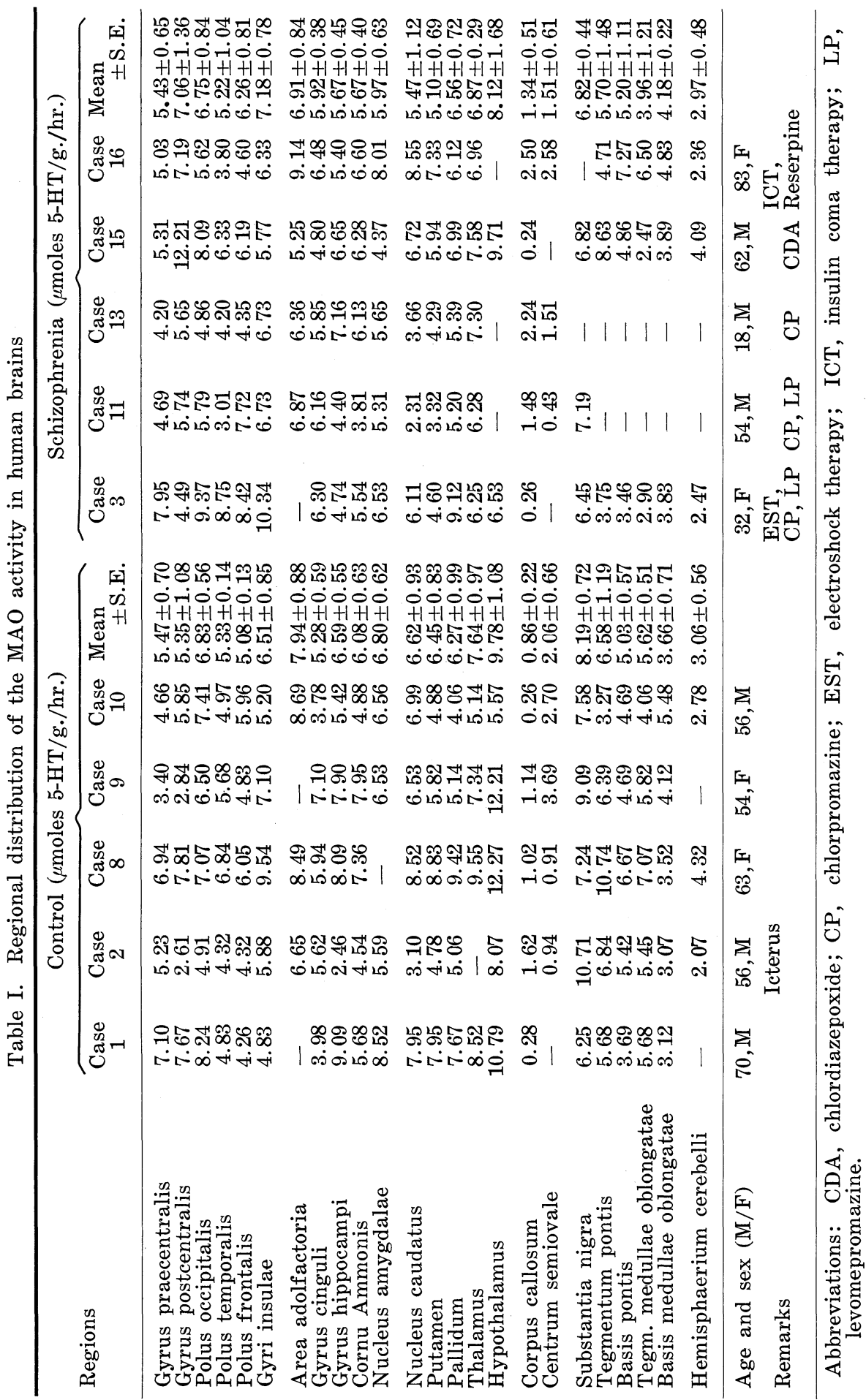


and during the period of storage at $-20^{\circ}$ were examined with brains of Wistar albino rats. As shown in Figs. 1 and 2, the results indicated that there was no remarkable change in the enzyme activity even when slaughtered animals were left for 24 hours at room temperature or brains were stored for 9 months at $-20^{\circ}$. In the present study it is assumed that this conclusion is valid to the case of human brains. Indeed, no correlation was found in the present study with human brains between the enzyme activity and the post-mortem period until autopsy or the period of storage of the brain at a low temperature.

The ratios of the activity on the wet weight basis to that on the protein weight basis did not differ significantly from each other among the regions examined. This finding indicates that there was not uneven loss of water among the regions examined during the storage of the whole brain at $-20^{\circ}$. Therefore, values for the activity in terms of $\mu$ moles $/ \mathrm{g} . / \mathrm{hr}$. were recorded in the present paper.

Results of the determination of the MAO activity in various regions of the control brains were recorded in Table I. All parts of the grey matter contained the considerable activity ranging from $5.08 \mu$ moles $/ \mathrm{g} . / \mathrm{hr}$. found in the frontal pole to $9.78 \mu \mathrm{moles} / . \mathrm{g} . / \mathrm{hr}$. in the hypothalamus, while the activity in the white matter was very low. In Case 2 the enzyme activity was remarkably low in some regions, especially in the caudate nucleus as compared with the corresponding values in other cases. Case 2 was different from other cases due to the complication of jaundice.

The distribution pattern of the enzyme activity in human brains is similar to that reported by the previous workers for the brains of various species of mammals.1),2),4),9) Strict comparison of the values reported by different authors for the enzyme activity in the brains of various species of animals is difficult, since the enzyme activity differs to the great extent according to the assay conditions, for instance by the concentration of substrate. Recently, Robins et $a l .5)$ have reported on the topographical distribution of 5 - $\mathrm{HT}$ and 5-hydroxytryptophan decarboxylase activity in human brains. No correlation was found between the amount of the amine and the activity of its synthesizing enzyme. The distribution of the MAO activity obtained in the present study does not parallel the distribution of 5-HT or of the activity of 5-hydroxytryptophan decarboxylase.

The distribution of the enzyme activity in the brains of schizophrenic patients is shown in Table I. Although the values in some regions were different to some extent from those in the control brains, none of the differences was statistically significant. Examining 
individual values for the activity in each case, it was noted that the enzyme activities in the caudate nucleus and the putamen in Cases 11 and 13 were considerably lower than those in Cases 15 and 16, the activities in Case 3 being intermediate. Cases 11, 13, and 3 were administered phenothiazines, whereas in Cases 15 and 16 only a small dose of chlordiazepoxide or reserpine but not phenothiazine was used as a drug-therapy. On the other hand, there is a difference in age between the two groups of patients. The number of cases is not sufficient for the present to draw a conclusion as to the factor to cause the difference in the enzyme activity between the groups of patients.

Table II. MAO activity in major systems of the brain

\begin{tabular}{lcccr}
\hline & \multicolumn{2}{c}{ Control } & \multicolumn{2}{c}{ Schizophrenia } \\
Systems (Number of regions) & $\begin{array}{c}\mu \text { moles } \\
\text { /g./hr. }\end{array}$ & Ratio & $\begin{array}{l}\mu \text { moles } \\
\text { /g./hr. }\end{array}$ & Ratio \\
\hline Cerebral cortex (6) & 5.34 & 100 & 6.32 & 100 \\
Limbic system (5) & 6.54 & 122 & 6.03 & 95 \\
Striatum (2) & 6.54 & 122 & 5.28 & 83 \\
Thalamus (1) & 7.64 & 142 & 6.87 & 109 \\
Hypothalamus (1) & 9.78 & 183 & 8.12 & 128 \\
Pallidonigral system (2) & 7.23 & 135 & 6.69 & 106 \\
Pontobulbar tegmentum (2) & 6.10 & 114 & 4.83 & 76 \\
\hline
\end{tabular}

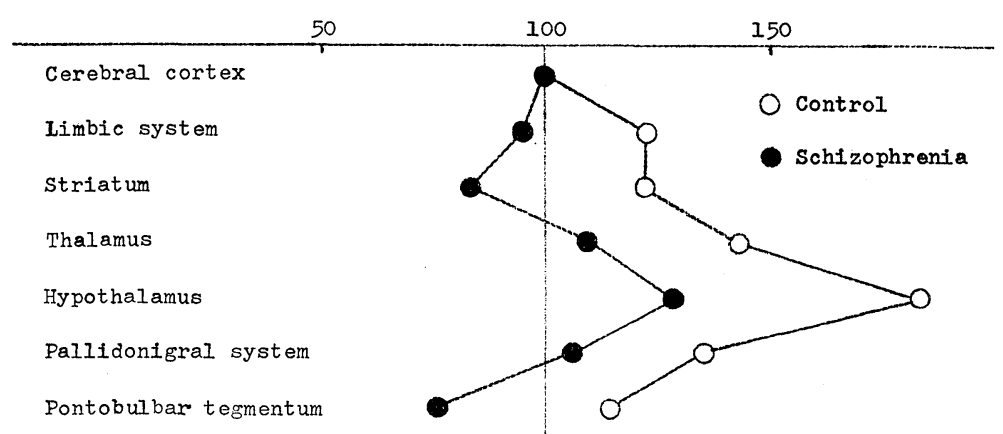

Fig. 3. Relative values of MAO activity in major systems of the brain.

In order to obtain a simplified picture of the distribution pattern of the enzyme activity in the brain, nineteen regions out of the twenty-four as specified in Table I were classified into seven systems with regard to the functional significance. The systems are listed in Table II together with the mean value of enzyme activities in each system and the ratio of the activity to that in the cerebral cortex. Apparently this operation has revealed a difference between the brains of schizophrenic and non-schizophrenic patients in the dis- 
tribution pattern of the enzyme activity. As visualized in Fig. 3, the relationship in the brains of schizophrenic patients between the neocortex and the limbic system, the striatum or the pontobulbar tegmentum as to the relative activity of MAO appears to be opposite to that in the control. The relatively lowered enzyme activity in the limbic system is of interest considering the finding obtained in the study with the methamphetamine-intoxicated cats. ${ }^{6)}$ Further studies are in progress to give conclusions to the problems presented in the present paper.

The authors wish to acknowledge the kind cooperation of Drs. K. Harada and T. Yoshida in dissecting human brains and the skillful technical assistance of Miss S. Motoike. This work was supported in part by grant from the Takeda Science Foundation.

\section{References}

1) Bogdanski, D. F., Weissbach, H., and Udenfriend, S. (1957): J. Neurochem., 1, 272.

2) Funatogawa, S. (1964): Psychiat. Neurol. Jap., 66, 743.

3) Lowry, O. H., Rosebrough, N. J., Farr, A. L., and Randall, R. J. (1951) : J. Biol. Chem., 193, 265.

4) McCaman, R. E., McCaman, M. W., Hunt, J. M., and Smith, M. S. (1965) : J. Neurochem., 12, 15.

5) Robins, E., Robins, J. M., Croninger, A. B., Moses, S. G., Spencer, S. J., and Hudgens, R. W. (1967): Biochem. Med., 1, 240.

6) Takano, K., Tanaka, I., and Funatogawa, S. (1967): Psychiat. Neurol. Jap., 69, 562.

7) Udenfriend, S. (1962): Fluorescence Assay in Biology and Medicine, p. 169. New York, Academic Press.

8) Utena, H. (1966): In Progress in Brain Research, vol. 21B, p. 192. Ed. by Tokizane, T., and Schadé, J. A. Amsterdam, Elsevier Publishing Company.

9) Weiner, N. (1960): J. Neurochem., 6, 79. 